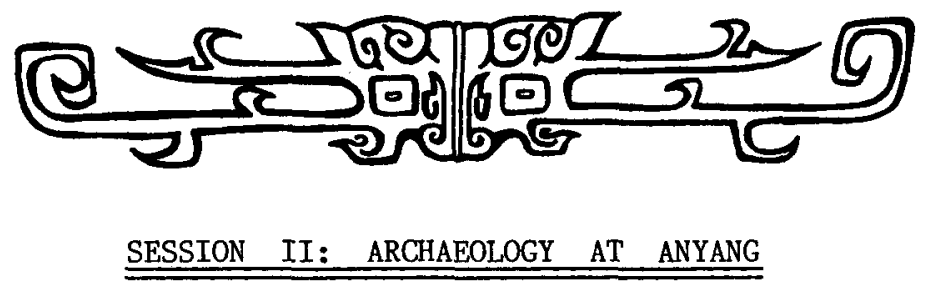

*5. KWANG-CHIH CHANG (Harvard University)

YINXU TOMB NUMBER FIVE AND THE QUESTION OF THE PAN GENG-XIAO XIN-XIAO YI PERIOD IN YINXU ARCHAEOLOGY

\title{
ABSTRACT:
}

At the time of the Shang's arrival at Yinxu their material culture was characterized by: (1) oracle-bone inscriptions; (2) bronze decor in Loehr Styles IV and V; (3) bronzes inscribed with societal emblems and ancestral "dedications"; (4) particular ceramic forms; (5) rammed-earth house foundations; and (6) pit graves lined with wooden chambers. These features appear for the first time in association with Tomb 5, that of $F u H a o$, the consort of Wu Ding. Shang cultural data at Yinxu earlier than the Tomb 5 period are scarce and scattered. They involve: (1) the architectural remains at Xiaotun before the rammed earth house foundations; (2) earlier Shang tombs (M188, 232, 333, 388); and (3) an earlier Shang tomb at Wuguancun Locus North. Conspicuous cultural changes took place from Pottery Period I (prior to the Tomb 5 period) to Pottery Period II (Tomb 5 period), including: (1) expansion of the area of occupation; (2) oracle-bone inscriptions, rammed-earth house foundations, and large tombs, all evidently associated with the royal house; (3) Period II pottery becomes predominant and Loehr's bronze Styles IV and $\mathrm{V}$ come to replace I-III, with inscriptions becoming numerous. It is suggested that the series of changes that occurred with the onset of the Tomb 5 period resulted from Pangeng's move of his capital to this site. If this is so, then the period of the three kings from Pangeng to Xiaoyi must be found within the period of Tomb 5 rather than within the Pottery Period I.

\section{DISCUSSION :}

Yang Xizhang (Institute of Archaeology, Peking) reminded the participants that there was still no unity about whether M5 belonged in Wu Ding's or Wu Yi's reign. Chang's paper made clear what farreaching implications a solution to the M5 dating question would have on all Shang materials. About the pre-M5 period, there were several questions on his mind: firstly, was it Pan Geng who moved his capital 
to Yinxu, or was his capital perhaps at Beimeng 北蒙; Secondly, if Pan Geng did move to Yinxu, how many years elapsed between his reign and the accession of Wu Ding? According to the contradictory written records, the timespan could be as short as 16 years, as $\mathrm{K}$. C. Chang seemed to believe in his paper, but it could have been as much as 53 years. It is difficult for archaeology to determine the length of any recognizable stratigraphic phase in terms of absolute time. At any rate, Zou Heng's Period I reaches into Wu Ding's reign.

His on-site experience at Anyang, Yang continued, had yielded some material that could prove helpful. Recent digs had uncovered oracle bones with characters resembling Tung Tso-pin's Period IV in association with Period I pottery (Zou's periodization), in an apparently undisturbed context. The archaic character of Period IV oracle inscriptions has long been noted; perhaps, the bones recently found represent a genuinely early style that was imitated in a later period. The consequence of this new find may be a re-dating of part of the oracle bones previously classed as Period IV. Furthermore, Yang considered the Jia group of palace foundations at Yinxu to be from Zou's Period I, whereas the two other groups date from the second or third period. Perhaps, more foundations from the early part of Wu Ding's reign will be discovered in the ongoing excavations. On the other hand, we now know that there are twelve -- no more -- large tombs at Xibeigang. If the first three kings after Pan Geng were buried at Yin, it cannot have been at the Xibeigang cemetery. Yang also noted that some of the pit-houses referred to by Chang actually dated from Dasikong II, not Yinxu I.

K. C. Chang replied that these explanations only underlined the urgent need for a master chronological framework encompassing all excavations so far done at Yinxu.

6. WANG GUTMIN (Institute of History, Peking)

A TENTATIVE DESCRIPTION OF THE CIVILIZATION OF THE MIDDLE PERIOD OF LATE SHANG

ABSTRACT:

The late Shang represents a peak in bronze culture, and was the culmination of a long period of development. The words of the Duke of Zhou in the "Wu yi" 無逸 chapter of the Shang shu that "The kings who arose after [Zu Jia], during their (whole) life en joyed ease .... After this there were none who had any chance of reaching a high age..." is not sufficient to be relied upon. Nor is it appropriate to evaluate the entirety of Late Shang history solely on the basis of the large number of oracle bones from the reign of Wu Ding. The primary purpose of this paper is to demonstrate, through an analysis of the contents of oracle-bone inscriptions from the Middle 